TITLE:

\title{
Size-related Egg Production in a Simultaneous Hermaphrodite, the Sea Hare Aplysia kurodai Baba (Mollusca: Opisthobranchia)
}

\section{$\operatorname{AUTHOR}(\mathrm{S}):$}

Yusa, Yoichi

\section{CITATION:}

Yusa, Yoichi. Size-related Egg Production in a Simultaneous Hermaphrodite, the Sea Hare Aplysia kurodai Baba (Mollusca: Opisthobranchia). PUBLICATIONS OF THE SETO MARINE BIOLOGICAL LABORATORY 1994, 36(4): 249-254

\section{ISSUE DATE:}

1994-11-15

URL:

http://hdl.handle.net/2433/176236

RIGHT: 


\title{
Size-related Egg Production in a Simultaneous Hermaphrodite, the Sea Hare Aplysia kurodai Baba (Mollusca: Opisthobranchia)
}

\author{
YoIchi Yusa \\ Seto Marine Biological Laboratory, Kyoto University, \\ Shirahama, Wakayama 649-22, Japan
}

With Text-figures $1-6$

\begin{abstract}
The relationship between body size and egg production was investigated in a simultaneous hermaphrodite, the sea hare Aplysia kurodai Baba. Individuals of similar size were experimentally paired and the pairs were kept isolated from each other in the laboratory. Under this condition, large individuals produced more eggs per day than small individuals, while the size of eggs did not change with adult body size. It is argued that the positive correlation between body size and egg production rate is likely to occur in field populations of this sea hare.
\end{abstract}

Key words: Aplysia kurodai, body size, egg production rate

\section{Introduction}

In most animals with separate sexes, large females produce more eggs than small females (Ridley, 1983). If this trend is caused by the difference in the amount of resources the females invest in reproduction, in simultaneous hermaphrodites large individuals will not necessarily produce more eggs than small conspecifics, since large ones may increase sperm production rather than egg production. However, the theory of sex allocation (Gharnov, 1982, 1987; Werren, 1980) predicts that large hermaphrodites should increase egg production rather than sperm production to maximize their reproductive success, provided that fertilization success of each sperm is similar among individuals of different sizes. Thus a positive correlation between body size and egg production is expected in some, or maybe most, hermaphroditic animals.

Several authors have shown that large individuals produce more eggs per brood than small individuals in hermaphroditic animals such as trematodes (Kearn, 1985), snails (Wolda, 1963; Baur, 1988; Baur \& Raboud, 1988; Tomiyama \& Miyashita, 1992), opisthobranch molluscs (Crozier, 1918; Ross \& Quetin, 1990) and barnacles (Barnes \& Barnes, 1968; Achituv \& Barnes, 1978). However, the larger brood size of large individuals does not necessarily reflect a higher egg production rate, for they may produce broods at a slower rate than small individuals. An actual correlation between body size and egg production rate has been shown in few hermaphroditic animals (Wolda, 1963; Kearn, 1985; Baur \& Raboud, 1988; Ross \& Quetin,

Publ. Seto Mar. Biol. Lab., 36(4), 249-254, 1994. (Article 18) 
1990). Moreover, if the size of eggs is related to the amount of resources they contain or to the survival rate of juveniles, information on egg size is important in considering sex allocation or reproductive success of individuals.

Sea hares of the family Aplysiidae are hermaphroditic opisthobranchs. Their copulation is usually non-reciprocal and received sperms are stored for several days (MacGinitie, 1934; Yusa, 1994). In the sea hares, positive correlations are reported between body size and the weight of individual egg strings (Kandel \& Capo, 1979) and between body size and the total weight of egg strings produced per unit time (Switzer-Dunlap \& Hadfield, 1979). Although these studies on egg string weight are suggestive, there is no direct evidence in sea hares that large individuals lay more eggs per unit time than small ones. In this paper I report the relationships of body size to the factors relevant to egg production rate in Aplysia kurodai Baba. The relationship of body size to egg size is also reported.

\section{Materials and Methods}

Sea hares lay long egg strings in a mass and several individuals often lay egg strings almost at the same time in the same place. Thus, when many individuals participate in the formation of an egg mass, it is usually difficult to identify the relative contribution of each individual. For this reason, experimental animals were kept in pairs and allowed to mate only within the pair.

Individuals of $A$. kurodai were collected from the rocky shore near the Seto Marine Biological Laboratory $\left(33^{\circ} 41^{\prime} \mathrm{N}, 135^{\circ} 20^{\prime} \mathrm{E}\right)$ on 15 th April 1993 . On the next day, they were weighed in the laboratory and eight pairs of similar sizes were chosen (the difference in weight between two individuals of a pair was less than $4 \mathrm{~g}$ ). They were weighed again at the end of the observation period (30th April), and the average value was adopted as their body size. Each pair was kept in a plastic bag $(28 \times 27 \mathrm{~cm})$ with continuous water flow, and fed with a sufficient supply of the green alga Ulva perlusa.

Animals were checked at least once a day between 16 th and 30 th April. Whenever an egg string was found, it was collected, labelled and fixed in 10\% sea water formalin until further examination. Sometimes an egg mass was made up of two strings of different colours and each string formed a distinct clump. On such occasions, each string was separated from the other and treated as one brood.

From November to December 1993, measurements of eggs were made. First, each egg string was weighed after excess fluid was removed. Three portions $(3-5 \mathrm{~mm}$ long) were cut out of it and weighed with a microbalance. The fragments were then put into Bouin's solution for ca. 4 weeks at room temperature, until the gelatinous layers around the egg capsules became fragile. Then the fragments were squashed on a slide glass and the number of eggs in them was counted on the screen of a projector at $\times 100$ (cf. Kandel \& Capo, 1979). Since the treatment in Bouin's solution appeared to shrink the eggs, eggs from the formalin-fixed egg strings were measured. Three portions were cut out of each string in which most $(>90 \%)$ of the eggs were at the 1-cell stage, and the diameters of two randomly chosen eggs in each portion (six for each string) were measured under a microscope at $\times 200$ with a digital micrometer.

\section{Results}

Eight pairs of $A$. kurodai (average body size of the pair ranged from 30.8 to $131.4 \mathrm{~g}$ ) produced $58 \mathrm{egg}$ strings (broods) during the 2-week observation period. The number of broods laid by each pair during the period varied from 2 to $10(0.07-0.36$ per individual per day; see Fig. 1), but there was no significant correlation between the average body size of the pair and the number of broods (Fig. 1). 


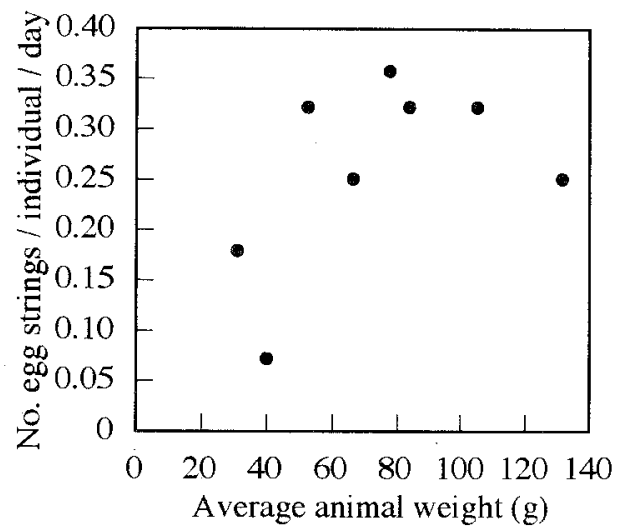

Fig. 1. Average body weight of the pair and daily brood production per individual (range: $0.07-0.36$ ). Correlation was not significant $(\mathrm{N}=8, \tau=0.31, \mathrm{P}>0.2 ;$ two-tailed Kendall's rank correlation).

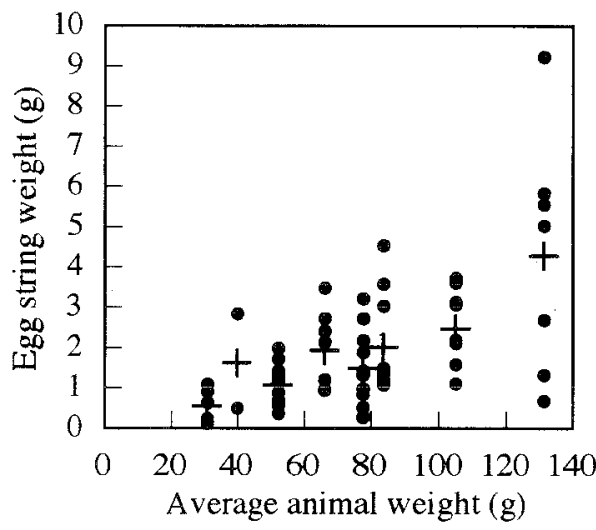

Fig. 2. Average body weight of the pair and egg string weight. Circle indicates individual string (range: $0.1-9.2 \mathrm{~g}$ ) and cross indicates the average of the pair $(0.6-4.3 \mathrm{~g})$. There was a positive and significant correlation between body weight and string weight, both for individual strings $(\mathrm{N}=58, \tau=0.40, \mathrm{P}<0.00001)$ and for the average $(\mathrm{N}=8, \tau=0.79, \mathrm{P}<0.01)$.
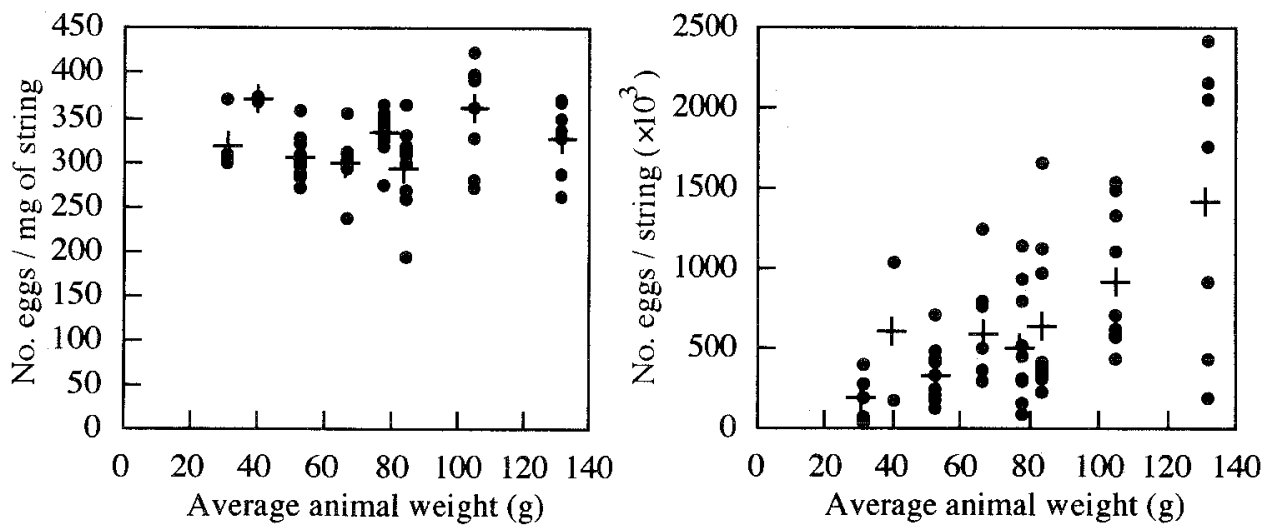

Fig. 3. Average body weight and egg density. Fig. 4. Average body weight and the number Gircle indicates individual string (range: $194-424$ eggs per $\mathrm{mg}$ ) and cross indicates the average (295-371). Correlation was not significant, either for individual strings $(\mathrm{N}=58, \tau=0.08$, $\mathrm{P}>0.3)$ or for the average $(\mathrm{N}=8, \tau=-0.07$, $\mathrm{P}>0.8$ ). of eggs in a string calculated from the data in Figs. 2 and 3 . Circle indicates individual string (range: $29 \times 10^{3}-2413 \times 10^{3}$ ) and cross indicates the average $\left(190 \times 10^{3}-1411 \times 10^{3}\right)$. There was a positive and significant correlation, both for individual strings $(\mathrm{N}=58, \tau=0.39, \mathrm{P}<0.0001)$ and for the average $(\mathrm{N}=8, \tau=0.71, \mathrm{P}<0.02)$. 
Fig. 2 shows the relationship between body weight and egg string weight. The weight of egg strings varied widely (0.1-9.2 g; see Fig. 2), but in contrast with the number of broods, there was a significant and positive correlation between body weight and egg string weight. A positive correlation was also shown when egg string weights were averaged for each pair (Fig. 2).

The relationship between body weight and the density of eggs, expressed as the number of eggs contained in $1 \mathrm{mg}$ of egg string, is shown in Fig. 3. The density of eggs had no correlation with adult body size, either for individual egg strings or for the average of the pair.

The number of eggs in each string was calculated from the weight of the string and its egg density. There was a tendency for large individuals to lay more eggs per brood than small individuals (Fig. 4).

Since large individuals laid more eggs per brood than small individuals (Fig. 4) and animal size did not affect the number of broods per day (Fig. 1), egg production rate should be higher for large individuals. In fact, there was a strong correlation between animal size and daily egg production (Fig. 5).

The average diameter of eggs varied little among broods or among pairs (Fig. 6). Correlation between body size and egg diameter was not significant, either for individual strings or for the average of the pair (Fig. 6).

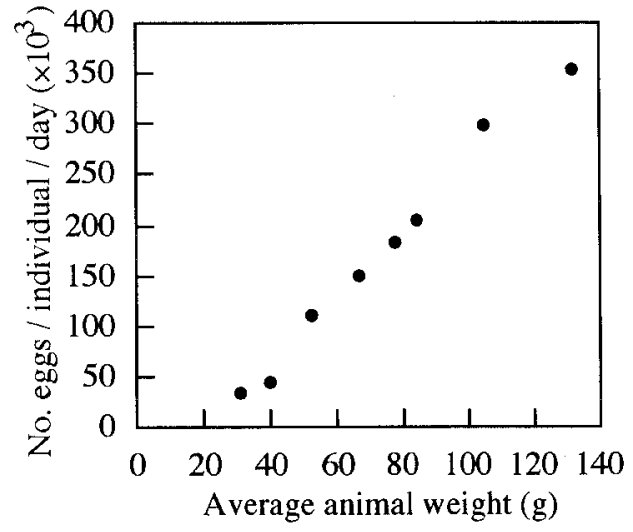

Fig. 5. Average body weight and daily egg production (range: $34 \times 10^{3}-353 \times 10^{3}$ ) calculated from the data in Figs. 1 and 4 . There was a positive and significant correlation $(N=8$, $\tau=1, \mathrm{P}<0.001$ ).

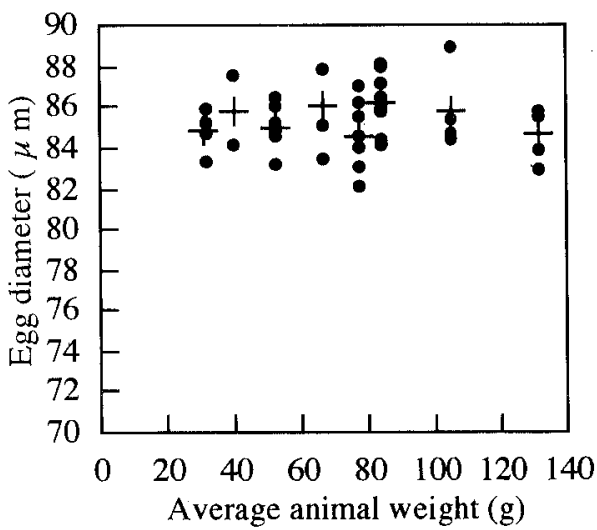

Fig. 6. Average body weight and average cgg diameter of each string. Circle indicates individual string (range: $82.0-89.0 \mu \mathrm{m}$ ) and cross indicates the average of the pair $(84.6-86.2$ $\mu \mathrm{m})$. Correlation was not significant, either for individual strings $(\mathrm{N}=41, \tau=0.07, \mathrm{P}>0.5)$ or for the average $(\mathrm{N}=8, \tau=0.07, \mathrm{P}>0.8)$. 


\section{Discussion}

Under the experimental condition in which individuals of similar sizes were paired and kept isolated from the other pairs, large individuals of $A$. kurodai produced more eggs per day than small individuals. This experimental condition, which allows only strict size-assortative copulation, is different from conditions in field populations of $A$. kurodai, where individuals of different sizes are found to copulate (Yusa, personal observation). Is it possible, then, that the higher egg production rate of large individuals in this study was caused by the size-assortative experimental condition and does not hold in field populations? If sea hares do not change the allocation of resources to sperm production and egg production (sex allocation) irrespective of the environmental conditions they meet, this possibility can be neglected and the experimental results reflect a similar situation in field populations. Alternatively, if sea hares have the ability to change their sex allocation according to the environment, the effect of the experimental conditions on the optimal sex allocation must be considered.

The optimal sex allocation of an hermaphroditic individual is determined by its expected reproductive success through sperms and eggs (Charnov, 1982; Fischer, 1981). Since the reproductive success through sperms of an hermaphrodite is affected by the total number of eggs it can potentially fertilize, both the number of mates (Charnov, 1982, 1987; Fischer, 1981; Sella, 1990; Raimondi \& Martin, 1991) and the number of eggs each mate produces (Charnov, 1982, 1987; Werren, 1980) should affect its optimal sex allocation, and hence, egg production rate. In this study, individuals of similar sizes were paired and isolated from others so that copulation could occur only within the pair. This treatment makes the number of mates the same (i.e. one, since Aplysia are self-infertile; MacGinitie, 1934; Zaferes et al., 1988; Yusa, 1994) for all the experimental individuals. It also makes the potential egg production rate of the partners in a pair similar, if the rate is somehow related to body size. Thus, the partner of a fecund individual should tend to be also fecund, and the partner of a less fecund individual less fecund. According to the sex allocation theory, the fecund individual (and also its partner) should divert some resources from egg production and produce more sperms to fertilize the partner's eggs, and a less fecund individual should produce less sperms and increase egg production. In short, size assortment makes the variation of egg production among individuals smaller, not larger: it does not explain the tendency for large individuals to lay more eggs per day. Hence, this tendency is likely to occur in field populations of A. kurodai.

The similarity in egg size among sea hares of different size implies that the quality of their eggs is also similar. If so, to obtain higher mating success, individuals as males might be expected to copulate with large, fecund female partners more frequently than with small, less fecund female partners. Indeed, there is evidence that such mate preference by male individuals occurs in a field population of this sea hare (Yusa, personal observation). 


\section{Acknowledgements}

I thank Marina Ichikawa and Bernhard Ruthensteiner for technical advice for the egg count, and Eiji Harada, Yasushi Harada, Graham G. Kearn and Shigeyuki Yamato for valuable comments on the manuscript.

\section{References}

Achituv, Y, \& Barnes, H. 1978. Some observations in Tetraclita squamosa rufotincta. J. Exp. Mar. Biol. Ecol., 31: 315-324.

Barnes, H. \& Barnes, M. 1968. Egg numbers, metabolic efficiency of egg production and fecundity; local and regional variations in a number of common cirripedes. J. Exp. Mar. Biol. Ecol., 2: 135-153.

Baur, B. 1988. Population regulation in the land snail Arianla arbustorum: density effects on adult size, clutch size and incidence of egg cannibalism. Oecologia (Berl.), 77: 390-394.

Baur, B. \& Raboud, C. 1988. Life history of the land snail Arianta arbustorum along an altitudinal gradient. J. Anim. Ecol., 57: 71-87.

Charnov, E. L. 1982. The Theory of Sex Allocation. Princeton University Press, Princeton. $355 \mathrm{pp}$. 1987. Sexuality and hermaphroditism in barnacles: a natural selection approach. In: F. R. Schram (ed.), Grustacean Issue, vol. 5. A. A. Balkema, Rotterdam. 89-103.

Crozier, W. J. 1918. Assortive mating in a nudibranch, Chromodoris zebra Heilprin. J. Exp. Zool., 27: 247-292.

Fischer, E. A. 1981. Sexual allocation in a simultaneously hermaphroditic coral reef fish. Am. Nat., 117: 64-82.

Kandel, P. \& Capo, T. R. 1979. The packing of ova in the egg cases of Aplysia californica. Veliger, 22: $194-198$.

Kearn, G. G. 1985. Observations on egg production in the monogenean Entobdella soleae. Int. J. Parasit., 15: 187-194.

MacGinitie, G. E. 1934. The egg-laying activities of the sea hare, Tethys californicus (Cooper). Biol. Bull., 67: 300-303.

Raimondi, P. T. \& Martin, J. E. 1991. Evidence that mating group size affects allocation of reproductive resources in a simultaneous hermaphrodite. Am. Nat., 138: 1206-1217.

Ridley, M. 1983. The Explanation of Organic Diversity. Clarendon Press, Oxford. 272pp.

Ross, R. M. \& Quetin, L. B. 1990. Mating behavior and spawning in two neustonic nudibranchs in the family Glaucidae. Amer. Malac. Bull., 8: 61-66.

Sella, G. 1990. Sex allocation in the simultaneously hermaphroditic polychaete worm Ophryotrocha diadema. Ecology, 71: 27-32.

Switzer-Dunlap, M. \& Hadfield, M. G. 1979. Reproductive patterns of Hawaiian aplysiid gastropods. In: S. E. Stancyk (ed.), Reproductive Ecology of Marine Invertebrates. University of South Carolina Press, Columbia. 199-210.

Tomiyama, K. \& Miyashita, K. 1992. Variation of egg clutches in the giant African snail, Achatina fulica (Ferussac)(Stylommatophora: Achatinidae) in Ogasawara Islands. Venus, 51: 293-301.

Werren, J. H. 1980. Sex ratio adaptations to local mate competition in a parasitic wasp. Science, 208: $1157-1159$.

Wolda, H. 1963. Natural populations of the polymorphic landsnail Cepaea nemoralis (L.). Arch. Néerl. Zool., 15: 381-471.

Yusa, Y. 1994. Factors regulating sperm transfer in an bermaphroditic opisthobranch, Aplysia parvula Mörch, 1863 (Gastropoda: Opisthobranchia). J. Exp. Mar. Biol. Ecol., 181: 213-221.

Zaferes, A., Skolnick, A. \& Tobach, E. 1988. Interindividual contact and copulation in Aplysia dactylomela. Mar. Behav. Physiol., 13: 221-238. 